\title{
Alpha, Beta, and Gamma HPV Infection in Juvenile Onset Recurrent Respiratory Papillomatosis
}

\section{Martina Bertinazzi ( $\square$ marti.berti1989@gmail.com )}

Università degli Studi di Padova: Universita degli Studi di Padova https://orcid.org/0000-0002-89725862

\section{Tarik Gheit}

IARC: International Agency for Research on Cancer

\section{Jerry Polesel}

National Cancer Institute CRO Aviano: Centro di Riferimento Oncologico

\section{Sandrine McKay-Chopin}

IARC: International Agency for Research on Cancer

\section{Cesare Cutrone}

Azienda Ospedale Università Padova: Azienda Ospedale Universita Padova

\section{Marianna Sari}

Azienda Ospedale Università Padova: Azienda Ospedale Universita Padova

\section{Marta Sbaraglia}

Azienda Ospedale Università Padova: Azienda Ospedale Universita Padova

\section{Angelo Paolo Dei Tos}

University of Padova: Universita degli Studi di Padova

\section{Piero Nicolai}

University of Padova: Universita degli Studi di Padova

\section{Massimo Tommasino}

IARC: International Agency for Research on Cancer

\section{Paolo Boscolo-Rizzo ( $\square$ paolo.boscolorizzo@units.it )}

Trieste University Integrated Healthcare Company: Azienda Sanitaria Universitaria Integrata di Trieste

\section{Research Article}

Keywords: Juvenile Respiratory Papillomatosis, Human Papillomavirus, Co-infections, Children, Prognosis

Posted Date: May 24th, 2021

DOl: https://doi.org/10.21203/rs.3.rs-552384/v1

License: (c) (1) This work is licensed under a Creative Commons Attribution 4.0 International License. 
Page 2/16 


\section{Abstract \\ Purpose}

The aim of our study is to evaluate the prevalence of different HPV genera - alpha, beta and gamma - in Juvenile onset Recurrent Respiratory Papillomatosis (JoRRP) and examine the association of type and genus-specific viral features with the clinical outcome of disease.

\section{Methods}

This retrospective observational study includes consecutive patients with JoRRP who were treated in a referral centre between October 2000 and October 2020. All patients underwent cold excision and laser vaporization of papillomatous lesions. Samples were analysed for the presence of 120 viral genotypes (22 alpha-HPV, 46 beta-HPV, 52 gamma-HPV) using a highly sensitive multiplex genotyping assay.

\section{Results}

Twenty patients with JoRRP, aged 0.3-11 years old, were included, with a median follow-up of 13.5 years. All samples were HPV DNA positive: 20 (100\%) for alpha-HPV DNA; 7 (35\%) for beta - HPV DNA; 0 for gamma-HPV DNA. Three groups were defined according to the number of infections: seven cases (35\%) with HPV mono-infection; ten cases (50\%) with HPV double-infection; three cases (15\%) with $\geq 3 \mathrm{HPV}$ infections. At diagnosis, patients with $\geq 3 \mathrm{HPV}$ infections reported higher median Derkay's score than those with mono-infection (21 vs 14, $P=0.018$ ). Number of HPV infections was also associated with clinical outcomes, with an average of 0.5 surgical procedures/year in patients with mono-infection, 1.2 for double-infection, 2.6 for $\geq 3$ infections $(P=0.006)$.

\section{Conclusion}

Despite the small sample size, these preliminary data support an association between the number of different alpha and beta HPV co-infections and the clinical severity of the disease.

\section{Introduction}

Juvenile onset Recurrent Respiratory Papillomatosis (JoRRP) is a rare and challenging HPV-induced disease, frequently associated with mucosal HPV-type infection, in particular HPV 6 and 11, and characterized by the growth of squamous papillomata in the airway epithelium [1].It is defined by the onset before 12 years of age with the peak of incidence being commonly before 5 years [2]. Because of JoRRP's typical recurrence, patients often require multiple surgical debulking procedures to maintain an airway patency [3]. 
There is currently no eradicative cure for JoRRP. Furthermore, no reliable markers predicting the course of the disease, the risk of recurrence or malignant transformation exist [4]. However, the new adjuvant therapies appear to be promising in improving the control of the disease [5]. It could be, therefore, interesting and innovating having biological markers that can guide clinicians to select patients eligible for adjuvant therapies.

Many studies have investigated whether the severity and aggressivity of JoRRP maybe influenced by the infection with mucosal HPV types, 6 and 11, but the results provided inconsistent and contrasting conclusions $[1,6]$. To the best of our knowledge, no study has ever investigated the prevalence of HPV genera other than mucosal alpha genus in JoRRP. Interestingly, some beta HPV types from species 3 appears to have dual tropism, being detected in nasal or anal mucosa and the skin $[7,8]$. Thus, in this study we have evaluated the prevalence of different HPV genera - alpha, beta and gamma, in JoRRP with a highly sensitive genotyping assays and investigated whether different pattern of HPV infection may influence the clinical outcome of the disease.

\section{Materials And Methods}

\section{Study population}

This observational study included 20 consecutive children aged $<12$ years old at onset of JoRRP, in a referral centre (Policlinico Universitario di Padova) between October 2000 and October 2018 and followed-up until October 2020. A clinical and surgical database of all patients, including age and Derkay's score [9] at onset, yearly number of surgical procedures since the diagnosis, duration of followup, surgical and controls videos, surgical and clinical outcomes have been maintained prospectively since October 2000. All patients were treated with both cold surgical and laser vaporisation with active aspiration by the same expert surgeon (CC) in the same single centre. The whole study was approved by the ethic committee for clinical experimentation of Treviso and Belluno provinces (Ethic votes: 345/AULSS9 and 421/AULSS9).

Inclusion criteria comprehended: a) diagnosis of JoRRP; b) age $\leq 12$ years old at onset; c) histological and clinical data available in hospital database; d) written consent for data processing.

Depending on clinical course of the disease, considering the number of surgical procedures/year and the presence of a longitudinal progression of papillomatosis, we stratified the patients in three groups: a. in remission; b. with persistence, c. in progression. We defined in remission patients with no evidence of papillomata in the past 5 years; with persistence the patients submitted to less than 4 surgical procedures in the last year and/or without a longitudinal progression of papillomatosis, and in progression the patient submitted to more than or equal to 4 surgical procedures in the last year and/or with a longitudinal progression of papillomatosis.

\section{Collection of samples and DNA extraction}


Paraffined tissue samples for molecular analysis were obtained from surgical specimens. Micro slices of all paraffined samples were shipped to the Infection and Cancer Biology Group at the International Agency for Research on Cancer in Lyon, France. DNA was obtained by an overnight incubation at $37^{\circ} \mathrm{C}$ of

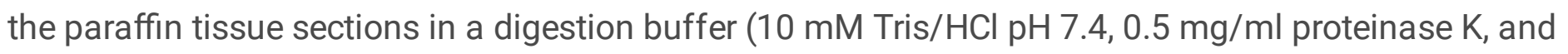
$0.4 \%$ Tween 20) [10]. To monitor the possible occurrence of cross-contamination between the different specimens during DNA extraction, tubes containing only buffer were also included (1 tube with buffer every 10 specimens).

HPV type-specific PCR bead-based multiplex genotyping assay (TS-MPG)

The identification of 120 viral genotypes was performed by using a high sensible type - specific multiplex genotyping assays (TS-MPG), which combine multiplex polymerase chain reaction (PCR) and bead-based Luminex technology (Luminex Corp., Austin TX, USA) as described in the literature [11, 12]. Multiplex type-specific PCR uses specific primers for the detection of 22 alpha-papillomavirus types (HPV6, 11, 16, 18, 26, 31, 33, 35, 39, 45, 51, 52, 53, 56, 58, 59, 66, 68 and b , 70, 73 and 82 ), 46 betapapillomavirus types (HPV5, 8, 9, 12, 14, 15, 17, 19, 20, 21, 22, 23, 24, 25, 36, 37, 38, 47, 49, 75, 76, 80, 92, $93,96,98,99,100,104,105,107,110,111,113,115,118,120,122,124,143,145,150,151,152,159$, 174) and 52 gamma-papillomavirus types (HPV4, 48, 50, 60, 65, 88, 95, 101, 103, 108, 109, 112, 116, $119,121,123,126,127,128,129,130,131,132,133,134,148,149,156,161,162,163,164,165,166$, $167,168,169,170,171,172,173,175,178,179,180,184,197,199,200,201,202)$. Primers for the amplification of beta-globin were also added to provide a positive control for the quality of the template DNA. Amplification of beta-globin gene showed that in all cases the samples contained good quality DNA. The results were expressed as mean fluorescence intensity (MFI) [13]. The cut off was computed by adding $5 \mathrm{MFI}$ to 1.1 times the median background value.

\section{Statistical analysis}

Differences in socio-demographic and clinical characteristics of the patients across strata were assessed with the Kruskal-Wallis test or Fisher's exact test. The values of $P$ reported in the tables are considered significant when $\leq .05$. For each patient and for each year after diagnosis, the cumulative number of surgical procedures was calculated as the total number of surgical procedures from the diagnosis.

\section{Results}

\section{Clinical results}

Patients' clinical data were included in Table 1. Twenty patients who met the inclusion criteria were included in the study. The median age at diagnosis was 3.0 years old (range 0.3-11.0 years old) and the male:female ratio was approximately 1:2. The median duration of follow up was 13.5 years (range 2-20 years) and the Derkay's score at onset (clinical and anatomical score) varied between 5 and 23 with a median value of 14. Papillomata demonstrated different localizations along the airways with different 
prevalence. As shown in Table 2, the larynx was the most involved site (95\% of cases). The median number of procedures/year at onset was 2, ranging between 1 and 10 . The total number of surgeries ranged from 1 to 45 with a median value of 9.5 , while the maximum number of surgeries/year ranged from 1 and 13, with a median value of 3 . All samples were HPV-DNA positive and they reported at least one infection for alpha-HPV DNA; 7 cases (35\%) were also positive for beta-HPV DNA, while no gammaHPV DNA was detected in any specimen (Table 1).

\section{Results of bio-molecular investigations}

Depending on the number of infections, patients were categorized into three groups (Table 2): 1) patients with HPV mono-infection (7 cases, 35\%); 2) patients with HPV double-infection (10 cases, 50\%); 3) patients with $\geq 3 \mathrm{HPV}$ infections (3 cases, $15 \%$ ). Thus, $65 \%$ of patients have multiple HPV infections. Of the 10 samples with double co-infection, $6(30 \%)$ showed an alpha-HPV co-infection (three patients with HPV6-11 and three patients with HPV11-16) while 4 samples (20\%) showed alpha and beta co-infection (HPV6-19; HPV6-111; HPV6-111; HPV6-17). Finally, the 3 samples (15\%) with co-infection of $\geq 3$ papillomavirus genotypes were all positive for alpha HPV11 associated with another alpha genotype (HPV6 or HPV16) and with an HPV beta genotype ranging in number from 1 to 2 (HPV6-11-100; HPV6-11111; HPV11-16-21-100). The maximum number of co-infections observed in the present series was 4.

\section{Clinical and Virological correlations}

The three groups showed similar age at onset. In all groups, the main site of papillomata was the larynx, involved in $100 \%$ of cases with co-infection and in $86 \%$ of patients with mono-infection. Although not significant, multiple localization was more frequent in patients with $\geq 3 \mathrm{HPV}$ infections than those with one or two co-infections (67\% vs 30\%, respectively). The Derkay's score at diagnosis increased with the increasing number of co-infections, reaching 21 for $\geq 3 \mathrm{HPV}$ co-infection compared to 9 for patients with mono-infection $(P=0.018)$ (Table 2). The median number of surgical interventions at onset was higher for patients with $\geq 3$ multiple infections, though not significant (Table 3). However, the maximum number of surgical procedures/year $(P=0.012)$, the average number of surgical procedures/year $(P=0.022)$ and the total number of surgeries $(P=0.006)$ increased with increasing number of HPV co-infections. Three patients were considered in progression and they were all co-infected patients: one positive for double coinfection and two positives for multiple co-infections. The majority of patient with HPV mono-infection (57\%) was clinically in remission, whereas no one showed progression (Table 3).

Clinical outcome was also evaluated as required number of surgical procedures after diagnosis. Interestingly, the average cumulative number of surgical procedures flattened after approximately 5 years from onset for patients with mono-infection or double-infections, even if at a lower level for the former than the latter (average cumulative number= 5.3 and 14.7, respectively). Conversely, patients with $\geq 3$ HPV infections showed an upward trend over the all period of observation, reaching an average cumulative number of 43.0 surgical procedures after 20 years from diagnosis (Figure 1). Cumulative number of surgical procedures was also calculated using information on HPV6 and HPV11 alone (Figure 
2). Patient with HPV6/HPV11 co-infection showed the worse clinical course, whereas those with HPV11 infection showed the best clinical course.

\section{Discussion}

To the best of our knowledge, this is the first study that analysed the presence of a large number of alpha, beta and gamma HPVs types in JoRRP using a highly sensitive method. The data show that all JoRRP were associated with infections of mucosal alpha HPV types 6 and 11, which are well-known etiological factors of JoRRP. In addition, several JoRRP were also positive for some beta HPV types. Despite the small study size, the findings highlight an association of multiple HPV infections with the severity of disease in comparison to single HPV infections.

The main problems of recurrent respiratory papillomatosis are still the lack of an eradicating treatment and the impossibility to predict its clinical outcome because of its unpredictable nature and the still limited knowledge on the pathogen-host interaction [14]. This lack of information has prompted many clinicians to try to provide a prognosis of the disease, looking for the risk factors most involved in the aggressiveness of RRP. Most of the available studies in literature found a correlation between the aggressiveness of RRP and the aetiology by HPV11 [15].

It has been assumed that HPV11 E7 may interact more effectively with the transporter associated with antigen processing subunit 1 (TAP1) than HPV6 E7, leading to reduced immune responses and the more severe disease course observed in HPV11 RRPs $[16,17]$. However, other studies did not provide evidence for the higher aggressive properties of HPV11 versus HPV6 ${ }^{1}$. Indeed, some studies reached opposite conclusions, being HPV6 more associate with higher JoRRP severity in comparison to HPV11 [18, 19]. Other studies highlight that age at diagnosis, rather than the genotype of HPV involved, can impact on the clinical history of the disease $[1,6]$.

Our findings showed that single infections have a lower prevalence than co-infections and that the latter have a much more aggressive outcome than the others which instead tend to stabilize after a follow-up of about 4 years. (Figure 1) Considering the results of prevalence of HPV genera (alpha - beta - gamma) and the clinical data, it is evident that in the present case series an increased number of co-infections was associated with increasing aggressiveness of the disease determined both by the number of surgical procedures and the longitudinal spread of the disease (Figure 1). On the other hand, by considering the clinical course of papillomatosis with respect to alpha-HPV infection only, it was observed that HPV11 is the genotype involved in a more aggressive course of the disease. However, it was clear only when HPV11 was associated with other viral genotypes (co-infections) but not in cases of mono-infection, where instead the disease has a more indolent course (Figure 2).

Multiple studies concerning the biological mechanism and the role of interactions and co-infections between different HPV genotypes were conducted on other widely spread HPV-related tumors [20]. Primarily on cervical cancer, about which several authors agree on the association between genotype- 
specific HPV interactions, multiple viral co-infections and increased risk of cancer onset. ${ }^{21}$ Concerning respiratory papillomatosis, in 2010 Donne and colleagues did not find a certain clinical difference between HPV6 and HPV11 and recognized the possible impact of untested HPV-variants co-infections on the clinical outcome of RRP [22].

Other authors had also highlighted the presence of co-infections in respiratory papillomatosis, considering both other viruses - such as EBV, HSV and CMV, and other alpha-HPV genotypes, assuming their co-presence as an additional risk factor for the clinical outcome of the RRP [23]. In 2015 Omland and colleagues decided to stratify RRP patients depending on alpha - HPV viral load without considering HPV co-infections. They finally demonstrate the absence of a correlation between the RRP prognosis and the HPV viral load, defined as irrelevant if $<5$ copies/cell [6]. Other authors, such as Buchinsky, excluded cases of alpha-HPV-DNA co-infections from their cluster because, in their opinion, it was impossible to determine which of the different involved genotypes was responsible for the clinical phenotype of the disease [1].

However, the data of the present study do not provide any evidence of a direct role of co-infections in determining the greater aggressiveness of the disease. It has been observed that immunosuppressed patients often harbour multiple oral HPV infections [24]. Thus, the association between the aggressiveness of JoRRP and multiple HPV infections may reflect patient's immuno-suppressive status which more directly may affect the aggressive course of the disease.

Limited sample size is the major limitation of the present study, and, therefore, the results should be considered as preliminary. Nonetheless, results are strongly indicative of a new prognostic trend in JoRRP that would benefit the inclusion of a larger sample for further validation. Indeed, small sample size mainly impact on false negative results as the study is not powered to detect small differences. Further, the small sample size did not allow multivariable analyses. Conversely, the homogeneity of patients, treated and followed up by the same centre, is to be account among study strength.

\section{Conclusions}

JoRRP still remains an investigating pathology in terms of treatment and clinical course. Both alpha and beta HPV genera may be involved in JoRRP pathogenesis and the number of different HPV-type coinfections may serve as a prognostic indicator of the clinical course of the disease. The results of this study, although preliminary and based on a small number of patients, underline the importance of a highly sensitive diagnostic method in this pathology.

\section{Declarations}

Acknowledgements: Where authors are identified as personnel of the International Agency for Research on Cancer/World Health Organization, the authors alone are responsible for the views expressed in this 
article and they do not necessarily represent the decisions, policy, or views of the International Agency for Research on Cancer/World Health Organization.

Funding: No funding was received to assist with the preparation of this manuscript

Conflicts of interest/Competing interests: The authors have no conflict of interests to declare that are relevant to the content of this article

Availability of data and material: All data and materials used in this study are now available in clinical database

Authors' contributions: All the authors have contributed actively to the study and have approved of the final version of the manuscript

Ethics approval: The whole study was approved by the ethic committee for clinical experimentation of Treviso and Belluno provinces (Ethic votes: 345/AULSS9 and 421/AULSS9)

Consent to participate: Informed consent was obtained from all individual participants or their caregivers included in the study

Consent for publication: Participants or their caregivers have given their approval for this study to be published

\section{References}

1. Buchinsky FJ, Valentino WL, Ruszakay N et al (2019) Age at diagnosis, but not HPV type, is strongly associated with clinical course in recurrent respiratory papilllomatosis. PLoS ONE 14(6):e0216697. https://doi.org/10.1371/journal.pone.0216697

2. Costa V, El-Achkar V, de Barros P et al (2020) Role of Epstein-Barr virus in the severity of recurrent respiratory papillomatosis. Laryngoscope 130(11). doi: 10.1002/lary.28465

3. Mammas IN, Dalianis T, Doukas SG et al (2019) Paediatric virology and human papillomaviruses: An update. Experimental Therapeutic Medicine 17:4337-4343. doi 10.3892/etm.2019.7516

4. Ribeiro Fortes $H$, Mussi von Ranke F, Escuissato DL et al (2017) Recurrent respiratory papillomatosis: A state-of-the-art review. Respir Med 126:116-121. doi 10.1016/j.rmed.2017.03.030.

5. Ryan MA, Leu GR, Upchurch PA et al (2021) Systemic Bevacizumab (Avastin) for Juvenile-Onset Recurrent Respiratory Papillomatosis: A Systematic Review. Laryngoscope 131(5):1138-1146. doi 10.1002/lary.29084

6. Omland T, Akre H, Lie KA et al (2014) Risk factors for aggressive Recurrent Respiratory Papillomatosis in adult and juveniles. Plos One 9(11):e113584. https://doi:10.1371/journal.pone.0113584 
7. Forslund O, Johansson H, Madsen KG et al (2013) The nasal mucosa contains a large spectrum of human papillomavirus types from the Betapapillomavirus and Gammapapillomavirus genera. J Infect Dis 208(8):1335-1341. doi 10.1093/infdis/jit326

8. Hampras SS, Rollinson DE, Giuliano AR et al (2017) Prevalence and Concordance of Cutaneous Beta Human Papillomavirus Infection at Mucosal and Cutaneous Sites. J Infect Dis 216(1):92-96. doi 10.1093/infdis/jix245

9. Derkay CS, Malis DJ, Coltrera MD et al (1998) A staging system for assessing severity of disease and response to therapy in recurrent respiratory papillomatosis. Laryngoscope 108:935-937. doi 10.1097/00005537-199806000-00026

10. Gheit T, Abedi-Ardekani B, Carreira C et al (2014) Comprehensive analysis of HPV expression in laryngeal squamous cell carcinoma. J Med Virol 86(4):642-646. doi 10.1002/jmv.23866

11. Corbex M, Bouzbid S, Traverse-Glehen A et al (2014) Prevalence of papillomaviruses, polyomaviruses, and herpesviruses in triple-negative and inflammatory breast tumors from Algeria compared with other types of breast cancer tumors. PLoS ONE 9:e114559. https://doi.org/10.1371/journal.pone.0114559

12. Schmitt M, Dondog B, Waterboer T et al (2010) Abundance of multiple high-risk human papillomaviruses (HPV) infections found in cervical cells analyzed by use of an ultrasensitive HPV genotyping assay. J Clin Microbiol 48:143-149. doi 10.1128/JCM.00991-09

13. Clifford GM, Vaccarella S, Franceschi S et al (2016) Comparison of two widely-used HPV detection and genotyping methods: GP5+/6 + PCR followed by reverse line blot hybridization and multiplex type-specific E7 PCR. J Clin Microbiol 54(8): 2031-2038. https://doi:10.1128/JCM.00618-16

14. Campisi P (2018) Recurrent Respiratory Papillomatosis. Springer International Publishing AG

15. Derkay CS, Bluher AE (2019) Update on Recurrent Respiratory Papillomatosis. Otolaryngol Clin N Am 52(4):669-679. doi 10.1016/j.otc.2019.03.011

16. Vambutas A, DeVoti J, Pinn W, Steinberg BM, Bonagura VR (2001) Interaction of human papillomavirus type $11 \mathrm{E} 7$ protein with TAP-1 results in the reduction of ATP-dependent peptide transport. Clin Immunol 101:94-99

17. Ivancic $R$, Iqbal $H$, deSilva $B$, Pan Q, Matrka $L$ (2020) Immunological tolerance of low-risk HPV in recurrent respiratory papillomatosis. Clin Exp Immunol 199(2):131-142. doi 10.1111/cei.13387

18. Mounts $\mathrm{P}$, Kashima H (1984) Association of human papillomavirus subtype and clinical course in respiratory papillomatosis. Laryngoscope 94:28-33. doi 10.1002/lary.5540940106

19. Padayachee A, Prescott CA (1993) Relationship between the clinical course and HPV typing of recurrent laryngeal papillomatosis. The red cross war memorial Children's hospital experience 19821988. Int J Pediatr Otorhinolaryngol 26:141-147. https://doi: 10.1016/0165-5876(93)90019-y

20. Dickson EL, Vogel RI, Geller MA, Downs LS Jr (2014) Cervical cytology and multiple-type HPV infection: a study of 8182 women ages 31-65. GynecolOncol 133: 405-408 https://doi: 10.1016/j.ygyno.2014.03.552 
21. Senapati R, Nayak B, Kar SK, Dwibedi B (2017) HPV genotypes co-infections associated with cervical carcinoma: Special focus on phylogenetically related and non-vaccine targeted genotypes. PLosONE 12(11):e0187844. doi 10.1371/journal.pone.0187844

22. Donne AJ, Hampson L, Homer JJ et al (2010) The role of HPV type in Recurrent Respiratory Papillomatosis. Int J Pediatr Otorhinlaryngol 74:7-14 https://doi: 10.1016/j.ijporl.2009.09.004

23. Pou AM, Rimmel FL, Jordan JA et al (1995) Adult respiratory papillomatosis: human papillomavirus type and viral coinfections as predictors of prognosis. Ann Otol Rhinol Laryngol 104:758-762. doi $10.1177 / 000348949510401002$.

24. Anaya-Saavedra G, Flores-Moreno B, Garcia-Carranca A, Irigoyen-Camacho E, Guido-Jimenez M, Ramirez-Amador V (2013) HPV oral lesions in HIV-infected patients: The impact of long-term HAART. J Oral Pathol Med 42:443-449. doi 10.1111/jop.12032

\section{Tables}

Table 1. Patients' clinical, socio-demographic and viral characteristics 


\begin{tabular}{|c|c|c|c|c|c|c|c|}
\hline \# & Sex & $\begin{array}{c}\text { Age } \\
\text { at onset } \\
\text { (years) }\end{array}$ & $\begin{array}{c}\text { Derkay's score at } \\
\text { onset }\end{array}$ & $\begin{array}{c}\text { Follow- } \\
\text { up } \\
\text { (y) }\end{array}$ & $\begin{array}{c}\text { Number of } \\
\text { HPV } \\
\text { co-infections }\end{array}$ & Alpha-HPV & Beta-HPV \\
\hline 10 & $\mathrm{~F}$ & 2.8 & 14 & 12 & 1 & HPV6 & - \\
\hline 17 & $F$ & 2 & 10 & 4 & 1 & HPV6 & - \\
\hline 18 & $F$ & 3 & 16 & 14 & 1 & HPV6 & - \\
\hline 19 & $\mathrm{~F}$ & 11 & 7 & 2 & 1 & HPV6 & - \\
\hline 12 & $\mathrm{M}$ & 2 & 9 & 7 & 1 & HPV11 & - \\
\hline 9 & $F$ & 5.3 & 5 & 5 & 1 & HPV11 & - \\
\hline 16 & F & 3 & 9 & 19 & 1 & HPV11 & - \\
\hline 15 & $F$ & 0.8 & 16 & 15 & 2 & HPV6 & HPV17 \\
\hline 3 & F & 0.3 & 17 & 10 & 2 & HPV6 & HPV19 \\
\hline 4 & $\mathrm{M}$ & 1.1 & 11 & 14 & 2 & HPV6 & HPV111 \\
\hline 7 & F & 4 & 9 & 19 & 2 & HPV6 & HPV111 \\
\hline 1 & $\mathrm{M}$ & 3.2 & 6 & 20 & 2 & $\begin{array}{l}\text { HPV6, } \\
\text { HPV11 }\end{array}$ & - \\
\hline 13 & $\mathrm{M}$ & 6 & 20 & 19 & 2 & $\begin{array}{l}\text { HPV6, } \\
\text { HPV11 }\end{array}$ & - \\
\hline 14 & F & 1.5 & 19 & 14 & 2 & $\begin{array}{l}\text { HPV6, } \\
\text { HPV11 }\end{array}$ & - \\
\hline 2 & $\mathrm{M}$ & 4 & 15 & 10 & 2 & $\begin{array}{l}\text { HPV11, } \\
\text { HPV16 }\end{array}$ & - \\
\hline 8 & $\mathrm{~F}$ & 2.1 & 14 & 9 & 2 & $\begin{array}{l}\text { HPV11, } \\
\text { HPV16 }\end{array}$ & - \\
\hline 11 & $\mathrm{~F}$ & 3 & 7 & 13 & 2 & $\begin{array}{l}\text { HPV11, } \\
\text { HPV16 }\end{array}$ & - \\
\hline 5 & M & 4 & 23 & 15 & 3 & $\begin{array}{l}\text { HPV6, } \\
\text { HPV11 }\end{array}$ & HPV111 \\
\hline 20 & $\mathrm{~F}$ & 3 & 19 & 6 & 3 & $\begin{array}{l}\text { HPV6, } \\
\text { HPV11 }\end{array}$ & HPV100 \\
\hline 6 & $\mathrm{M}$ & 2 & 21 & 19 & 4 & $\begin{array}{l}\text { HPV11, } \\
\text { HPV16 }\end{array}$ & $\begin{array}{l}\text { HPV21, } \\
\text { HPV100 }\end{array}$ \\
\hline
\end{tabular}

Table 2. Clinical and socio-demographic characteristics at diagnosis according to number of co-infections 


\begin{tabular}{|c|c|c|c|c|c|c|c|c|c|}
\hline & \multirow{2}{*}{\multicolumn{2}{|c|}{ All }} & \multicolumn{6}{|c|}{ HPV co-infection } & \multirow{3}{*}{ p-value } \\
\hline & & & \multicolumn{2}{|c|}{ One } & \multicolumn{2}{|c|}{ Two } & \multicolumn{2}{|c|}{ Three or more } & \\
\hline & $\mathrm{n}$ & $(\%)$ & $\mathrm{n}$ & $(\%)$ & $\mathrm{n}$ & $(\%)$ & $\mathrm{n}$ & $(\%)$ & \\
\hline Total & 20 & $(100)$ & 7 & (35) & 10 & $(50)$ & 3 & $(15)$ & \\
\hline \multicolumn{10}{|c|}{ Age at diagnosis (years) } \\
\hline Median & \multicolumn{2}{|c|}{3.0} & \multicolumn{2}{|c|}{3.0} & \multicolumn{2}{|c|}{2.6} & \multicolumn{2}{|r|}{3.0} & 0.720 \\
\hline Min, Max & \multicolumn{2}{|c|}{$(0.3,11.0)$} & \multicolumn{2}{|c|}{$(2.0,11.0)$} & \multicolumn{2}{|c|}{$(0.3,6.0)$} & \multicolumn{2}{|c|}{$(2.0,4.0)$} & \\
\hline Sex, female & 13 & (65) & 6 & $(86)$ & 6 & $(60)$ & 1 & (33) & 0.216 \\
\hline \multicolumn{10}{|l|}{ Localization } \\
\hline Pharynx & 2 & $(10)$ & 1 & (14) & 1 & $(10)$ & 0 & $(0)$ & 1.000 \\
\hline Larynx & 19 & (95) & 6 & $(86)$ & 10 & $(100)$ & 3 & $(100)$ & 0.500 \\
\hline Trachea & 5 & $(25)$ & 1 & $(14)$ & 2 & $(20)$ & 2 & $(67)$ & 0.228 \\
\hline Bronchus & 1 & (5) & 0 & (0) & 0 & $(0)$ & 1 & (33) & 0.150 \\
\hline Lung & 1 & $(5)$ & 0 & $(0)$ & 0 & $(0)$ & 1 & $(33)$ & 0.150 \\
\hline Multiple & 6 & $(30)$ & 1 & $(14)$ & 3 & $(30)$ & 2 & (67) & 0.274 \\
\hline \multicolumn{10}{|c|}{ Derkay's score at diagnosis } \\
\hline Median & & 14 & & 9.0 & & 14.5 & & 21 & 0.018 \\
\hline Min, Max & & 23) & & $5,16)$ & & 20) & & $19,23)$ & \\
\hline \multicolumn{10}{|c|}{ Duration of follow, up (year) } \\
\hline Median & & 3.5 & & 7.0 & & 4.0 & & 15.0 & 0.159 \\
\hline Min, Max & & 20) & & 2, 19) & & 20) & & $6,19)$ & \\
\hline
\end{tabular}

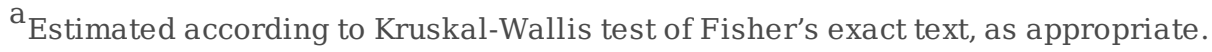

Table 3. Clinical history according to number of co-infections 


\begin{tabular}{|c|c|c|c|c|c|c|c|c|c|}
\hline & \multirow{2}{*}{\multicolumn{2}{|c|}{ All }} & \multicolumn{6}{|c|}{ HPV co-infection } & \multirow{3}{*}{ p-value ${ }^{a}$} \\
\hline & & & \multicolumn{2}{|c|}{ One } & \multicolumn{2}{|c|}{ Two } & \multicolumn{2}{|c|}{ Three or more } & \\
\hline & $\mathrm{n}$ & $(\%)$ & $\mathrm{n}$ & $(\%)$ & $\mathrm{n}$ & $(\%)$ & $\mathrm{n}$ & $(\%)$ & \\
\hline Total & 20 & (100) & 7 & (35) & 10 & $(50)$ & 3 & (15) & \\
\hline \multicolumn{10}{|c|}{ Number of surgeries/year at diagnosis } \\
\hline Median & \multicolumn{2}{|c|}{2.0} & \multicolumn{2}{|r|}{2.0} & \multicolumn{2}{|c|}{2.0} & \multicolumn{2}{|r|}{8.0} & 0.387 \\
\hline Min, Max & \multicolumn{2}{|c|}{$(1,10)$} & \multicolumn{2}{|c|}{$(1,3)$} & \multicolumn{2}{|c|}{$(1,7)$} & \multicolumn{2}{|c|}{$(1,10)$} & \\
\hline \multicolumn{10}{|c|}{ Maximum number of surgeries/year } \\
\hline Median & \multicolumn{2}{|r|}{3} & \multicolumn{2}{|c|}{2.0} & \multicolumn{2}{|c|}{3.5} & \multicolumn{2}{|r|}{8.0} & 0.012 \\
\hline Min, Max & \multicolumn{2}{|c|}{$(1,13)$} & \multicolumn{2}{|c|}{$(1,3)$} & \multicolumn{2}{|c|}{$(1,13)$} & \multicolumn{2}{|c|}{$(4,10)$} & \\
\hline \multicolumn{10}{|c|}{ Average number of surgeries/year } \\
\hline \multirow{2}{*}{$\begin{array}{l}\text { Median } \\
\text { Min, Max } \\
\end{array}$} & \multicolumn{2}{|c|}{1.2} & \multicolumn{2}{|r|}{0.5} & \multicolumn{2}{|c|}{1.2} & \multicolumn{2}{|r|}{2.6} & 0.022 \\
\hline & \multicolumn{2}{|c|}{$(0.1,4.3)$} & \multicolumn{2}{|c|}{$(0.1,2.3)$} & \multicolumn{2}{|c|}{$(0.2,1.7)$} & \multicolumn{2}{|c|}{$(2.4,4.3)$} & \\
\hline Total number & f su & geries & & & & & & & \\
\hline Median & & 9.5 & & 3.0 & & 15 & & 39 & 0.006 \\
\hline Min, Max & & ,45) & & , 10) & & 28) & & $26,45)$ & \\
\hline Clinical outcor & & & & & & & & & \\
\hline Remission & 10 & $(50)$ & 4 & $(57)$ & 6 & $(60)$ & 0 & $(0)$ & 0.161 \\
\hline Persistence & 7 & $(35)$ & 3 & $(43)$ & 3 & $(30)$ & 1 & (33) & \\
\hline Progression & 3 & (15) & 0 & $(0)$ & 1 & $(10)$ & 2 & (67) & \\
\hline
\end{tabular}

$\mathrm{RE}$ : in remission; PE: with persistence; PR: in progression.

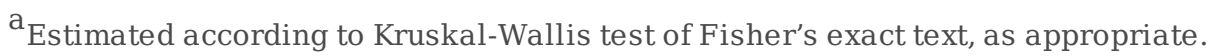

\section{Figures}




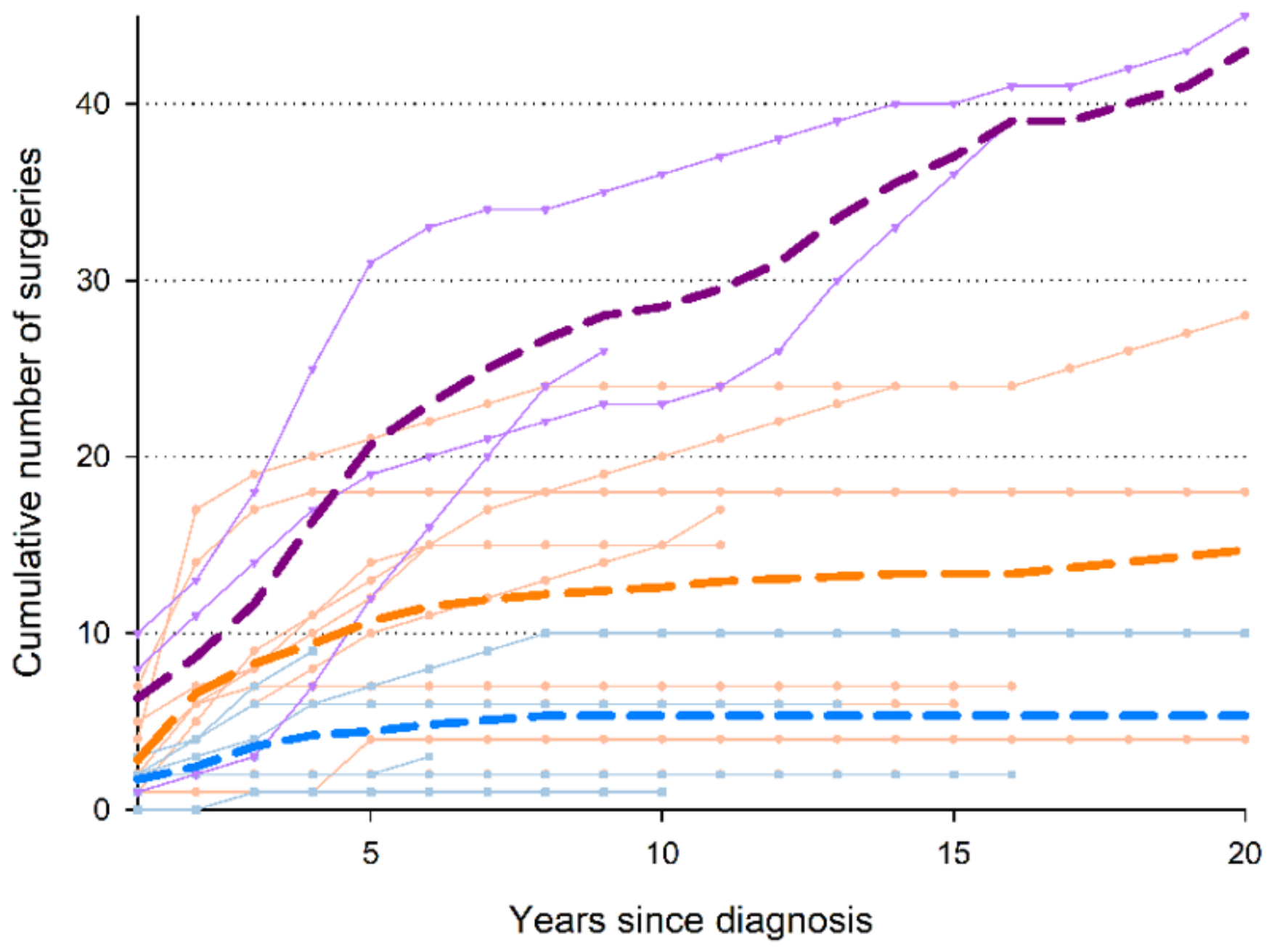

Number of HPV type infections:

2 3 or more

Figure 1

Cumulative number of surgeries according to number of co-infection with alpha-HPV and with beta-HPV 


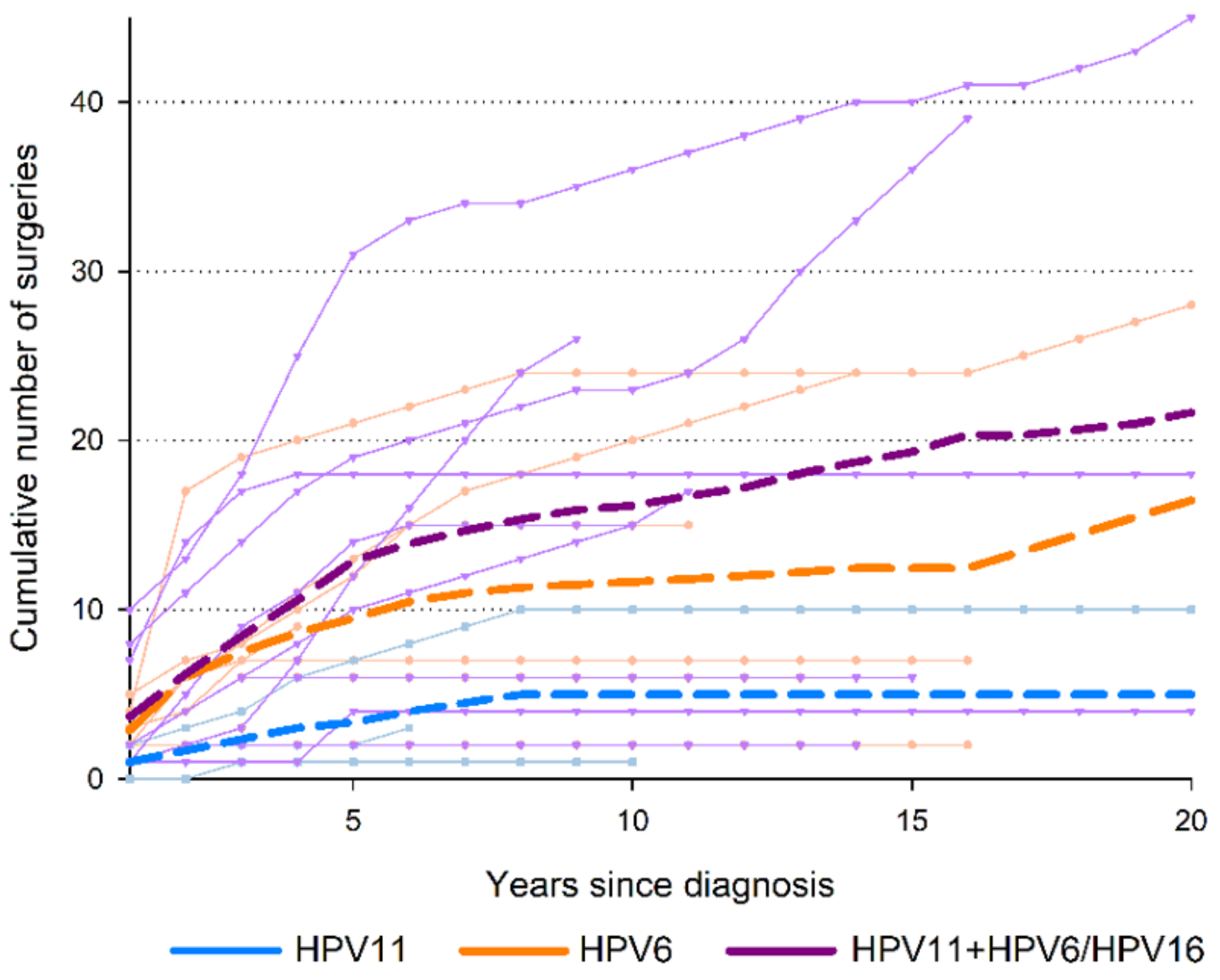

Figure 2

Cumulative number of surgeries according to alpha-HPV infections 